\title{
AN INTERPRETATION OF JOHN LOCKE'S CLASSIFICATION OF TRUTH ${ }^{i}$
}

\author{
RICHARD REILLY \\ Rice University
}

In Book IV of An Essay Concerning Human Understanding, ${ }^{2}$ John Locke presents what apparently amount to four different classes of truth, based on two sorts of criterion: the type of ideas contained in a proposition, and the type of connection existing between those ideas. According to the first criterion, any truth will be either "chimerical" or "real," (577) depending on whether or not the ideas signified conform to archetypes. So, for example, "All centaurs are animals" is chimerical because "centaur" signifies an idea that has "not an agreement with the reality of things." (577) On the other hand, if "these ideas, thus marked by sounds, agree to their Archetypes," $(578)^{3}$ then the truth is real. The second criterion, meanwhile, divides truths between the categories "instructive" and "trifling," according to whether a proposition presents us with new knowledge, or merely trifles with words. This depends on whether or not one idea in the proposition contains the other. Propositions wherein one idea does contain the other include "All purely identical Propositions" (609) such as "A soul is a soul;" (610) and propositions wherein "a part of the complex Idea, which any Term stands for, is predicated of that Term," (617) as in "Gold is a metal." (617) All these are "no better than trifling" (611) being, at best, only about the signification of words. Instructive truths, however, are those in which one term is predicated of another, the idea

${ }^{1}$ For the sake of simplicity we will, for the most part, restrict our discussion to universal truths which contain ideas of substances.

${ }^{2}$ John Locke, An Essay Concerning Human Understanding, ed., Peter $\mathbf{H}$. Nidditch (Oxford: Clarendon Press, 1975). All references to Locke's Essay are to this edition.

${ }^{3}$ Some question may arise as to how propositions should be classified wherein one term is real, the other chimerical. Are they half-real, halfchimerical? Examples given by Locke seems to suggest that, if either idea in the proposition is chimerical, the proposition itself is also chimerical. For example, the discussion of truth in Chapter V, Sections 7 and 8, seems to intend that "All Centaurs are animals" be considered chimerical, although "animals" apparently signifies a real idea. The interpretation of truths presented in this paper makes clear why any truth containing a chimerical idea should be classified as chimerical, regardless of the nature of the other idea. 
being neither identical with nor contained in the idea signified by the subject term. ${ }^{4}$ In this case "we are taught something more than barely what the word ... stands for." (614) Combining these criteria we see that every true proposition will fall under one of four categories, as shown below.

\begin{tabular}{c|c|c|}
\multicolumn{1}{c}{} & \multicolumn{1}{c}{ trifling } & instructive \\
\cline { 2 - 3 } chimerical & $\begin{array}{c}\text { trifling \& } \\
\text { chimerical }\end{array}$ & $\begin{array}{c}\text { instructive \& } \\
\text { chimerical }\end{array}$ \\
\cline { 2 - 3 } real & $\begin{array}{c}\text { trifling \& } \\
\text { real }\end{array}$ & $\begin{array}{c}\text { instructive \& } \\
\text { real }\end{array}$ \\
\hline
\end{tabular}

Or so, at least, it appears, until we take note of the fact that, in speaking of these different types of truth, Locke makes rather confusing use of his terminology. Over and over again, Locke refers to "trifling" truths as "only verbal" or "barely verbal," while calling "instructive" truths "real." Verbal and real, however, are the same terms he has used in other places when discussing chimerical and (of course) real truths. Hence it seems that the sign "verbal" represents two of Locke's notions: that of chimerical truths and that of trifling truths; while "real" apparently signifies both instructive truths and truths in which ideas agree with their archetypes. The instances of this are indeed numerous: too numerous to mention all here. ${ }^{5}$ Together they suggest, however, the following possibility: that there are not four categories of truth, as previously believed. Rather, truth may be only "twofold: either purely verbal and trifling . . . or real and instructive." (576) In other words, Locke may in fact have intended that the classes of trifling truths and chimerical truths be viewed as coextensive, as well as the classes of instructive and real truths. A careful examination of the nature of propositions and the ideas they contain shall reveal how this could be so. Indeed, we shall find, first of all, that chimerical instructive

'Unfortunately, no concise statement is given by Locke of the nature of instructive truths. That their defining characteristic in non-containment can be inferred from Chapter VIII, Sections 3 (16-23), 6, 8, and 9.

${ }^{5}$ Examples can be found throughout Book IV, Chapter VIII. See especially Sections 12 and 13, where trifling truths are called "barely verbal" and "only verbal." Also, Sections 8 and 9, where "instructive" and "real" seem to be used interchangeably. Compare these to Chapter 5, Section 8 and 9 , where "verbal" and "real" apparently refer to propositions containing "chimerical" and"real" ideas. Chapters 6 and 7 provide numerous other examples. 
instructive truths are, quite simply, impossible, and that what appear to be trifling real truths are in fact meant by Locke to be classified along with trifling chimerical truths as "verbal." If this is so, Locke's confusing use of terms may be seen not as careless or inaccurate, but rather, intentional, all truths meant to be delineated as simply verbal or real.

Previous authors who have written on the subject of instructive and real truths have come to a different conclusion. Noting the fact that Locke uses "real" in reference both to truths about real ideas, as well as to instructive truths, they have concluded that Locke had in mind two different notions of real truth/knowledge. A.D. Woozley, for example, believes Locke sometimes uses "real knowledge" to mean "knowledge of what is real," $(T, 145)^{6}$ and sometimes to mean "what really is knowledge." $(T, 145)$ In the first category he places truths "where we have agreement between ideas and the reality of things;" $(T, 145)$ i.e. truths where the ideas signified are ideas of real substances, as well as truths of applied mathematics. These are truths which tell us something about the real world. In the second category he places truths such as those of pure mathematics. (T,145) Richard Aaron and R. S. Woolhouse are in apparent agreement with this view. ${ }^{7}$ Pure mathematics is thought to provide knowledge of the second kind--what really is knowledge--because mathematical propositions can be both instructive--the idea signified by the subject not being contained in the idea signified by the predicate--and certain, because we perceive that the latter idea is a necessary consequence of the former. But, Woozley suggests, although such truths really are true, they nevertheless tell us nothing about the reality of things, and therefore do not provide real knowledge of the first type.

Although the interpretation of the Essay which follows does not focus upon mathematical truths, we shall find reason to suspect that Woozley's distinction between two types of real knowledge is not a distinction Locke would have wished to make. In the case of propositions about substances, at least, Locke calls the instructive truths "real" because he believes instructive truths tell us something about the real world. In fact, it will be found that calling a truth "instructive" is virtually synonymous, for Locke, with calling it a "truth about reality." When, therefore, Locke refers to the truths of mathematics, or even to truths of morality, as instructive and real, he may well intend that these also provide knowledge of reality, and not just that they "really are" knowledge. At the same time, we shall find that there are a large number of truths which Woozley would place in his

6A.D. Woozley, "Some Remarks on Locke's Account of Knowledge," in Locke on Human Understanding, ed., I. C. Tipton (Oxford: Oxford University Press, 1977). All references to Woozley are to this edition.

${ }^{7}$ See Richard Aaron, John Locke. (London: Oxford University Press, 1964) pp. 232-234; and R. S. Woolhouse, Locke's Philosophy of Science and Knowledge. (New York: Barnes and Noble, 1971) pp. 10-16. 
first category of real knowledge, but which Locke believes tell us nothing about reality. These are the trifling truths about real ideas, which Locke classifies as "verbal." In other words, the truth which Woozley thought belonged to a second category of real knowledge, Locke may have thought belonged to Woozley's first category; and many of the truths which Woozley thought belonged to his first category of real knowledge, Locke may have thought belonged to another category entirely.

Let us begin, then, with instructive truths, and a consideration of why instructive truths perhaps must be real. That this is what Locke intends seems clear from the moment he first distinguishes trifling and instructive truths, saying of the latter that they are the "Object of that real Knowledge which we have spoken of already." (576) "That real Knowledge" apparently refers to that described in Chapter IV, "Of the Reality of Knowledge," which, one may recall, had as its object truths involving real ideas; i.e. ideas which agree with their archetypes. Why, then, would Locke also believe that instructive truths are the object of this real knowledge?

Before we can answer this, we had best divert our path briefly to a consideration of truth in general, and what is involved in a proposition being true or false. Truth, according to Locke, "properly belongs only to propositions," (574) and signifies "nothing but the joining or separating of signs, as the things signified by them do agree or disagree one with another." (574) By joining or separating signs--that is, words or names--we "put them into a kind of Proposition affirmative or negative." (576) Having two or more ideas in our mind, we perceive or imagine an "agreement or disagreement" between them, and using words to represent these ideas, we create a proposition that endeavors to express this agreement or disagreement." For example, "The ball is blue" is a proposition which joins the signs "ball" and "blue," affirming that the two ideas--ball and blue-"agree" with each other. Likewise, "The ball is not red" separates the signs "ball" and "red," in the form of a negative proposition about the relationship of the ideas ball and red. We should also remind ourselves that agreement and disagreement are by Locke equated with connection and repugnancy; as he tells us in Chapter I of Book IV that knowledge is "the perception of the connexion and agreement, or disagreement and repugnancy of any of our Ideas." (525) Locke's definition of truth might therefore be restated as follows: "Truth . . . signifies ... nothing but the joining or separating of signs, as the things signified by them" are connected or repugnant "one with another." (574) 9 For a proposition to be true, therefore,

${ }^{8}$ For present purposes we restrict ourselves to propositions containing verbal signs, although it is clear from other passages that ideas themselves may be considered signs.

${ }^{9}$ Consideration of Locke's four different types of connection/repugnancy unfortunately lies beyond the scope of this paper. In general, however, we 
the ideas signified must actually be connected or repugnant with each other as the proposition claims they are or are not. Hence, if there is a connection between the ideas signified by "ball" and "blue," then "the ball is blue" is true, while "the ball is not blue" and "the ball is red," are both false.

An instructive truth, therefore, will be one which joins signs as their ideas are actually connected, yet where the one idea is not contained in or identical with the other. Let us consider, then, a proposition that possesses the form of an instructive chimerical truth: such as "all centaurs have wings," which asserts a connection between the idea signified by "wings" and the idea signified by "centaur." If this proposition is to be instructive, the idea of wings must not be contained in the idea of centaur. Since the latter is identified by Locke as "a rational Creature, consisting of a Horse's Head, joined to a body of humane shape," $(374)$ this first condition seems to be satisfied. Yet if it is also to be true, the idea signified by wings must actually agree, or be connected, with the idea of centaur. We may ask, however, whether or not there could be any sort of connection between wings and centaur, if the idea of centaur is chimerical and does not contain the idea of wings. Locke's answer, we shall find, is that without existence in reality, there is no connection, and if this is the case, instructive truths containing chimerical ideas will be impossible.

It is in fact clear that Locke believes there are virtually no connections between the simple ideas which make up our complex idea of a substance and other ideas not contained therein, except via the real essence. If, for example, our proposition is "gold is malleable,"

let the complex idea of gold be made up of which soever of its other qualities you please, malleableness will not appear to depend on that complex idea nor follow from any simple one contained in it. The connexion that Malleableness has (if it has any) with those other Qualities being only by the intervention of real constitution of its insensible parts. (583) (emphasis added)

In other words, unless "gold is malleable" is a trifling proposition (such that the idea of gold contains the idea of malleable), we cannot be certain it is true, for there is no connection between the complex idea of gold and the idea of malleable, except via the real essence which the ideas depend on. "For it is the real Constitution of its insensible Parts, on which depend all those Properties of Colour, Weight, Fusibility, Fixedness, etc, which are to be found" (419) in our ideal of gold. The same, of course, holds for all ideas,

will use the terms in one of two ways: (1) To refer to connections of identity or diversity, where a truth is trifling; or (2) To refer to whatever other sort of connection exists--of relation, co-existence, or real existence-- where a truth is instructive. Since our discussion focuses on truths about substances, co-existence will usually be meant. 
of substances." 10 The nature of instructive truths is therefore such that they must also correspond to the definition of real truths given in Brok IV, Chapter 5. "So far as these ideas, thus marked by Sounds, agree to their Archetypes, so fare only is the truth real." (578) An instructive truth's ideas must agree to their archetypes in order for any connection or agreement to exist between them at all. The problem, of course, for a proposition such as "Centaurs have wings" is that chimerical ideas have no real essence, no archetypes existing in nature. They are ideas of substances which "tacitly refer" (372) to reality, yet "have no foundation" (372) in it. Therefore it is obvious: if no connection exists between the ideas themselves, and no real essence exists to establish some connection, propositions with the form of instructive chimerical truths, joining chimerical ideas wherein one is not contained in the other, cannot in fact be truths at all. ${ }^{\text {ll }}$ Chimerical

${ }^{10}$ See also Book IV, Chapter III, Sections 11-14, and Chapter VI, Sections 6$10,15$.

1'It might be objected that the connection could be established by the real essence a chimerical substance would have, if it existed. I. E. a centaur, were it to exist, would have a certain real essence which would give rise to other qualities. Locke, however, makes it fairly clear that there is only a oneway relationship bet ween real essence and nominal essence. A real essence gives rise to certain simple ideas; but a nominal essence gives rise to no particular real essence. Indeed, substances with the same nominal essence may have different real essences which give rise to different qualities. (See Chapter VI, section 8.) Since, then, there is no guarantee that there is a specific real essence which centaurs would have if they existed, the assumption underlying the objection is undercut. (Thanks to Mark Kulstad for this.) 


\section{INTERPRETATION OF JOHN LOCKE}

propositions can only be trifling, when one idea contains the other, or else they are false. ${ }^{12}$

True propositions, therefore, if instructive, must be real; but does the converse hold as well? That is, if a truth contains real, and not chimerical, ideas will it necessarily be instructive? It is all too easy to find examples of such propositions which are, nevertheless, trifling. Most of Locke's own examples seem to be of this sort, as in "oyster is oyster" (610) and "All gold is fusible." (612) "Oyster is oyster" is an example of the first sort of trifling proposition, merely affirming a term of itself. "Gold is fusible," meanwhile, is an example of the second sort, asserting that gold--which is defined in part as fusible--is fusible. Both propositions also join ideas which conform with, and have been found, in reality, hence they seem to be real trifling propositions. This, however, contradicts the suggested interpretation that trifling propositions are never real. Could we perhaps argue that they must somehow in fact be instructive propositions? Clearly not, for Locke himself states: "these obviously . . . appear to contain no instruction in them; for when we affirm the same Term of it self, whether it be be realy verbal, or whether it contains any clear and real idea, it shows us nothing." (609)

Nevertheless, we may still find reason to believe that such propositions are to be classified as verbal, along with chimerical truths. For although these trifling propositions contain ideas which are real, they

${ }^{12}$ We can see that "Centaurs have wings" is false because the idea signified by centaur does not contain the idea of wings. This, of course, give rise the problem of how to refer to truths such as "Centaurs do not have wings," where the signs are "separated" as the ideas are in fact repugnant with each other. Here it is plausible to suggest that since the connection is one of "diversity," which Locke treats as one with "identity," (525-526) that such a truth is trifling. Moreover, one can see that " a million of such propositions" (609) might be made (Centaurs do not have six legs. Centaurs don't have scales. Etc.) though we will "not know one thing in the world thereby." (609)

Further evidence that truths wherein the connection is one of diversity are to be considered trifling may be found in early drafts of the Essay. For example,

We have a certain knowledge that one idea is not another; for our perceptions of those simple ideas are so clear, distinct, and manifest to us that we never mistake the idea of red for that of sweet, or extension for color ... But all this knowledge ... is but of our own imaginations within us." (B, 85-86) [Se note 15.]

See also Draft A, pp. 52-53 for a similar discussion of "universal negative propositions." 
nevertheless tell us nothing about reality, making no reference to it. This claim will require some explanation. To aid in approaching it, let us ask: what exactly do trifling propositions tell us?

Locke is more than willing to answer this question for us. First, speaking of identical propositions, such as "oyster is oyster," (610) he tells us that "Any very ignorant person ... may make a million of Propositions, of whose truth he may be infallibly certain, and yet not know one thing in the World thereby." (609) Trifling propositions, whether or not they contain real ideas, tell us nothing about the world. What do they tell us? Of the first sort of trifling proposition, he says, "They teach nothing but what every one who is capable of discourse knows without being told, viz. that the same term is the same term, and the same Idea the same Idea." (611) Similar are these comments about the second sort of trifling proposition: which "carry no Knowledge with them, but of the Signification of Words, huwever certain they be." (613) "Gold is fusible" thus at best only tells us what "gold" means. Likewise: "'Every Man is an animal, or living Body,' is as certain a Proposition as can be; but no more conducing to the Knowledge of Things than to say, A Palfrey is an ambling Horse ... both being only about the signification of words." (613) Finally, in concluding the chapter on trifling propositions, Locke says again, of both sorts, that they are "purely about the signification of Words, and contain nothing in them but the Use and Application of these signs." (617) It is, moreover, clear throughout the chapter that these comments about trifling truths apply to those containing real ideas as well as those containing chimerical ideas. Thus, whether the words joined signify chimerical or real ideas, a trifling truth about them is only about their signification, not about reality.

Most interesting, however, is this passage:

He that hath liberty to define, i.e. to determine the signification of his Names of Substances (as certainly every one does in effect, who makes them stand for his own ideas), and makes their Significations at a venture, taking them from his own or other Men's Fancies, and not from an Examination or Enquiry into the Nature of Things themselves, may with little Trouble, demonstrate them one of another, according to those several Respects and mutual Relations he has given them one to another; wherein, however Things agree, or disagree, in their own Nature, he needs mind nothing but his own Notions, with the Names he hath bestowed upon them. (615-616)

These mutual relations are brought about "by making them, in respect of one another, more or less, or equally comprehensive" (616) in their definitions. Here Locke has summarily explained what goes on in the making of trifling propositions. Everyone decides for himself, in effect, what complex idea each word will stand for, as Locke explains in Book III, Chapter VI. 
Most Men, wanting either Time, Inclination, or Industry enough for this, even to some tolerable degree, content themselves with some few obvious, and outward appearances of Things, thereby readily to distinguish and sort them for the common Affairs of Life: And so, without further examination, give them names, or take up the Names already in use. (457)

People aren't generally able to make a careful examination into nature, hence they make the signification of their general terms, "at a venture," only with as much care as is needed for common usage. Of course, in making a complex idea of substance the mind "never puts any together that do not really, or are not supposed to co-exist." (456) Yet men "generally content themselves with some few sensible obvious Qualities," (456) this being all that is needed for common affairs. These nominal essences will often, therefore, be "very imperfect," (457) never containing all the ideas "which are united in nature." (457) Moreover, different men will often signify by the same word very different ideas. "It is plain, that this complex Idea ... is, by different Men, made very differently; by some more, and others less accurately." (458) For example, one man's definition of "Man" might be "Animal Rationale," (456) another might have an idea "like that Picture, which the Painter makes of the visible Appearances joyned together;" (607) while another might add "Laughter, and Rational Discourse." (607) One word--"Man"-may in this manner signify very different ideas in the minds of different men.

Chimerical ideas, meanwhile, are a special case of this making of nominal essences: an exception to the way ideas are generally formed. For:

No body joins the Voice of a Sheep, with the Shape of a Horse; nor the Colour of Lead, with the Weight and Fixedness of Gold, to be the complex Ideas of any real Substances, unless he has a mind to fill his head with Chimeras. (455-456)

Normally, in making complex ideas of substances, the mind "only follows Nature," (455) albeit, as we've seen, only imperfectly. But the mind may create chimerical ideas, which do not follow nature, nor are meant to be the ideas "of any real substances."

Having made them, however, "more or less, or equally comprehensive" any of these ideas, real or chimerical, may be demonstrated one of another in various ways. Hence, returning to Chapter VIII, Section 9, Locke tells us that ideas such as

Substance, Man, Animal, Form, Soul, Vegetative, Sensitive, [and] Rational--|all of which appear to be real ideasl--may, with great Truth, be joined negatively and affirmatively in Propositions, as their relative Definitions make them fit to be so joined; and Propositions 
consisting of such Terms may, with the same clearness, be deduced one from another, as those that convey the most real Truths, and all this, without any Knowledge of the Nature or Reality of Things existing without us.(615) (emphasis added)

In other words, we may make trifling propositions, which contain "real" ideas and so appear to be real truths, without any knowledge of reality. All we need know are the definitions of the words: the significations we have given them. Hence, if the signification of "man" includes "animal" and "rational," "Negroes are men," will be true. But if the signification is "like that picture," and if that picture includes "White or Flesh-colour," (617) "Negroes are not men" will be true. Such is the nature of trifling truths. They are certainly true, but teach us nothing.

We've shown, therefore, why trifling propositions are said to be only verbal, and not real. Although they may contain real ideas, they are nevertheless only about the signification of words, and not about reality. It may still be pointed out, however, that for a proposition to be real in the sense of Chapter V, Sections 8 and 9, all that Locke requires is that the ideas conform with reality. Trifling propositions might therefore be purely verbal in one sense, but real in another.

Yet upon close inspection of Chapter V, where Locke distinguishes real truth from chimerical, we find still more evidence that chimerical truths and "trifling real" truth are to be classed together as "Verbal."

Truth, as well as Knowledge may well come under the distinction of Verbal and Real; that being only verbal Truth, wherein Terms are joined according to the agreement or disagreement of the ldeas they stand for; without regarding whether our ldeas are such as really have, or are capable of having, an Existence in Nature. (577-578), wherein Terms are joined according to the agreement or disagreement of the Ideas they stand for; without regarding whether our ldeas are such as really have, or are capable of having, an Existence in Nature. (577-578)

Notice here that the phrase "without regarding . . letc)" does not refer to the ideas contained in a proposition: rather, it refers to the unmentioned maker of the proposition, to that person's act of joining the terms. An "only verbal" proposition is one in which one does not regard, in making the proposition, whether or not the ideas really have or are capable of having an existence in nature, but rather, only regards the agreement or disagreement between the ideas themselves. Which is to say, they are joined without any knowledge of the real existence of things, but only as the ideas are made fit to be joined or separated. Hence this definition--which immediately follows that defining verbal truths as those in which the ideas signified "have not an agreement with the reality of things" (577)-may actually be read as expanding upon that definition in such a way that 
allows trifling propositions about real ideas to be included: for real ideas might also be joined without regarding whether or not they have or are capable of existing. In any case, whether or not Locke meant this definition to include "trifling real" truths, it is clear that it is much the same as that description of trifling truths, "wherein, however things agree or disagree in their own nature, he needs mind nothing but his own notions." According to both descriptions--of verbal truths, in Chapter 5; and of trifling truths, Chapter 8-the maker of the propositions need only regard his own notions, the ideas themselves, and the agreement or disagreement they have with each other. Where this is done the proposition is only verbal, whether or not the ideas are such as really exist.

Thus we can see why Locke referred to chimerical truths also as "barely nominal," as well as "only verbal." As we saw earlier, all chimerical truths must be trifling. Which is to say, all chimerical truths are "barely nominal," barely about nominal essences; or "only verbal," only about the signification of words. So it is also where the trifling proposition contains real ideas. To know its truth we need only regard the complex idea-the nominal essence-which we have ourselves created, and we are told nothing about reality thereby. Nothing, that is, but how to refer to it: "Every man is an animal (makes) me know but this, that body, sense, and motion, or power of sensation and moving, are three of those ideas that I always comprehend and signify by the word man; and where they are not to be found together, the name man belongs not to that thing." (613) In other words, such a trifling proposition tells us only of the ideas contained in the nominal essence of man, and further lets us know that, where we don't find the ideas of "body, sense, and motion" (etc) in an existing object, we don't signify that thing by the name Man. The same, of course could very well have been said of "Every centaur is an animal." It tells us only of the nominal essence of centaurs, and that we must not call any real thing by that name if it does not contain "Body, Sense, and Motion, or power of Sensation and Moving."

The case is similar with the other sort of trifling proposition: "centaur is centaur" and "gold is gold" tell us not even how to signify things in the world. They assert only that an idea is itself; but those ideas could be anything. Hence "the same word may with great certainty be affirmed of itself, without any doubt of the truth of any such proposition; and let me add, also, without any real knowledge." (609) We can be absolutely certain that such triflings are true, but we are taught nothing about reality thereby.

The problem we face now is this: whether or not Locke did intend to classify truths as we have suggested--all instructive truths real, all chimerical truths trifling, and all trifling truths, containing chimerical or real ideas, as barely nominal or verbal-it is nevertheless obvious that the definition Locke gives of real truths in Chapter 5 applies just as well to trifling propositions which contain real ideas as it does to instructive 
truths. "They contain real truth" Locke says, "when these things are joined as our ideas agree, and when our ideas are such as we know are capable of having an existence in nature." (578) By this definition, "gold is gold" would be real, if we know our idea of gold is capable of existing in nature. Again "so far as these ideas, thus marked by sounds, agree to their archetypes, so far only is the truth real. (578) In which case, "gold is gold" is real in so far as the idea signified by gold agrees to its archetype in reality. Moreover, we should note that these two definitions of real truth are made in response to the objection that "if Truth be nothing but the joining or separating of Words in Propositions, as the Ideas they stand for agree or disagree in Men's Minds ... by this account, it amounts to no more than the conformity of Words, to the Chimaeras of Men's Brains." (577) Hence a proposition such as "All Centaurs are Animals" (577) is just as true as "All Men are Animals." (577) "But of what use is all such Truth to us? (577) Locke asks. It is in response to this question that he distinguishes verbal from real truths, defining the latter in the two ways shown above. The implication seems to be that "All Centaurs are Animals" is only verbal, while "All Men are Animals" is to be considered real, purely on the basis of the type of ideas contained in the proposition. In fact, it must further be noted that, in this context, at least, "All Men are Animals" is trifling: for

the Words are put together according to the agreement of the Ideas in our Minds: And the agreement of the Idea of Animal with that of Centaur, is as clear and visible to the Mind, as the agreement of the Idea of Animal, with that of Man." (577)

This could not be the case if the proposition were instructive, for there would then be no "clear and visible" connection between the ideas, as we have seen ( $p$. 7). It therefore seems that Locke intends this trifling proposition, "All Men are Animals" to be considered real.

All this indeed places us in a quandary. Nevertheless, we must take note of the general nature of Locke's discussion which is, quite, simply, confused. Indeed, it is this confusion which gave rise to the present inquiry. At the end of Chapter 5, Section 6, Locke equates verbal truths with trifling truths, yet a page later apparently defines verbal truths as those which contain chimerical ideas. Likewise, "real" seems in Section 6 to mean "instructive," but shortly thereafter apparently refers to truths containing real ideas. What are we to make of this?

Some light might be shed if we step back and examine some of the earlier writings which the Essay, and this confusion, grew out of. Perhaps different streams of Locke's thought-one concerning trifling and instructive truths, the other chimerical and real ideas--came together in Chapter 5 and blended in a most confusing way. Confusing, at least, to us. 
The first step we should take is to the "View of the Essay," from Lord King's The Life of John Locke. ${ }^{13}$ There Locke condenses the whole of Chapter 5 's discussion of verbal and real truths into the following:

Truth also is two-fold, either real or barely verbal. Real truth in any proposition is when the terms are affirmed or denied as the ideas themselves agree to their archetypes. Verbal truth is when the affirmation is made according to the agreement of our ideas, but the ideas themselves have no conformity with their archetypes. $(K, 392)$

Two facts in particular we should note about this passage. First of all, it can easily be seen that it is a combination of the last sentence from Section 6 of Chapter 5, (which identified truths as "twofold . . Either purely Verbal, and trifling ... or Real and instructive"), plus the definitions of Verbal and Real Truths given in Sections 8 and 9. In this respect, it supports the interpretation presented in this papers, for the combination of these passages into one suggests that the apparently four types of truth are indeed only two. At the same time, however, the terms "trifling" and "instructive" are absent, and the definitions given of verbal and real truths are those which concern the nature of the ideas contained in the proposition, not the connection existing between them. It is difficult, therefore, to make any conclusions with regard to this passage.

We must go back to the Drafts of 1671, to Draft A especially, for more substantial evidence as to Locke's intentions. Therein we may find good indication of what Locke meant by verbal and real truths. From the very beginning, in fact, Locke makes the following clear: that he wants to "distinguish between the understanding of wonds and knowledge of things." [sic] $(A, 5)^{14}$ Which is to say, anticipating what follows, that he wants to distinguish between verbal and real truths/knowledge. This project, he hopes, will alleviate some of the "doubt confusions and errors" $(A, 5)$ in men's minds; hence, (fortunately for us), he spends much time in consideration of when truth is only about the ideas in our minds, and when it is about things existing without us.

The first sort of truths he considers are, essentially, those trifling truths we have been discussing. For example:

when I say a man is rational or hath the power of reasoning, it hath one of these two meanings

${ }^{13}$ Lord King, The Life and Letters of John Locke. (New York: Burt Franklin, 1972)

14John Locke, An Early Draft of Locke's Essay, eds. R.I. Aaron and Jocelyn Gibb. (Oxford: Clarendon Press, 1936). All references to Draft A are to this cdition. 
1. either that the power of reasoning belongs to or is included in that Idea which I have framd and call man, and then the proposition is certainly true and is only verbal and reaches certainly noe farther than my owne Ideas and the words or names I apply to them." Isic| (A, 27)

So, we can be certain of such "trifling" propositions, wherein one idea is contained in the other, but the truth is only verbal: only about our ideas and the words which signify them. lf, however, the one idea is not contained in the other, then saying "man is rational" means

2. ... that where the 7 foregoeing Ideas meet together there this 8 th is certainly also, and then the proposition is real, i.e. of things realy without my minde but is not certainly true ..." (A, 27)

"Man," in this example, signifies a collection of seven ideas listed earlier. ${ }^{15}$ Locke suggests, therefore, that by joining "rationality" with "man,"-the former not contained in the latter-one tells us something about reality, not just about one's ideas. This example is thus particularly informative, for only one proposition-"man is rational"--is referred to. The ideas it contains are apparently real. Yet when one idea is contained in the other, the proposition tells us only of ideas in our minds, and not of things existing without us. It may contain real ideas, but is not about reality ... unless the one idea does not contain the other, in which case it is about reality.

Throughout the following pages Locke continues to work out his distinction between only verbal and real propositions, repeatedly stressing that verbal propositions, wherein one idea contains or is identical with the other, are "little better than trifling with words," (A.49) and give us no knowledge of things in reality..$^{16}$ And so we eventually come to this familiar passage:

he that hath liberty to define his owne words as certainly every one doth who makes them stand for his own ldeas, and make their signification without taking them from his observation of things may

${ }^{15}$ The "7 foregoeing Ideas" are:

1. A face usual to that species which though consisting of many particular ldeas for brevitys sake and the thing being obvious I take for one.

2 . Two hands with five fingers on each.

3. Two legs.

4. Upright posture.

5. Liveing.

6. A power of laughing.

7. A power of speakeing. (A, 27)

i6see Draft A, pp. 25, 26, 29, 42, and especially 44-54. 
with little trouble demonstrate them one of an other, wherein, however things agree or disagree in their owne nature, he need mind noething but his owne notions with the names he hath bestowed upon them." $(A, 48)$

It is evident that Locke's notion of trifling/verbal truths is already fairly well developed, much as it will appear in the Essay. Frequently the words in Draft A echo what is said in Chapter VIII (and other parts of Book IV) of the Essay. In two passages on instructive truths, however, the "echo" in Draft $A$ is perhaps clearer in its intention. First Locke tells us: "all universal propositions that are instructive (i.e. informe us any thing about the nature qualities and operations of things existing without us) are all uncertain." (A,46-47) Locke's concern here is with certainty of knowledge, but it is clear that the clause in parentheses virtually defines instructive propositions as those that tell us "the nature qualities and operations of things existing without us." That is, instructive truths tell us something about reality. This also, Locke tells us, holds for Mathematical truths. "Mathematical universal propositions are both true and instructive because as those ldeas are in our minds soe are the things without us." ( $A, 51)$ Here it is again clear that by "instructive" Locke means that the proposition tells us of "things without us." (Although it is not clear from this passage how mathematical truths are distinguished from trifling truths such as "all gold is yellow.") Due to the nature of mathematical ideas, things in reality will agree as the ideas themselves agree, and so mathematical truths are more than just verbal.

Yet it is also clear in Draft $A$ that it is the non-containment relationship between the ideas signified that makes a truth instructive. For example:

he that shall tell me that in what ever thing Body Sense motion reason and laughter were united, that thing had a notion of god, haveing a notion of god, not being included in the definition of the word Homo, made indeed an instructive but not a Certain Proposition $(A, 51)$

Apparently, then, it is by virtue of this non-containment relationship that a true proposition tells us about reality. An instructive truth tells us that where we find in reality one set of ideas, there we find joined with them another. So, if our idea of man does not include having a notion of God, the proposition "Man has a notion of God" tells us that wherever we find in reality those ideas collected in the nominal essence of "man," there is a connection in reality between those ideas and "haveing a notion of god." And this is why in Draft A Locke tells us that the truth of instructive propositions about substances can only "be knowne and made out by history and enquiry into particulars which is the foundation of knowledge of things." ( $A, 51)$ We must study Men, and see if they actually have a notion of God, to discover the truth of "Man has a notion of God." In this way, 
enquiry into particular things gives us knowledge, though it be uncertain, of the truth of instructive propositions, that being how we see whether or not connections do really exist between the ideas.

This, then, explains why, in the Essay, while talking about instructive truths Locke repeatedly refers to them as real, and why they are said to be the object of real knowledge. Instructive truths are called real because they tell us about reality, not just about our ideas, and this is so precisely because of the fact that in an instructive truth one idea doesn't contain the other. Moreover, instructive truths must contain real ideas in order that there be some sort of connection between the ideas, arising from the real essence. Trifling truths, however, provide no real knowledge, no knowledge of things, as they reach no farther than our own ideas.

It can therefore be seen that Locke had this distinction between verbal and real propositions in mind practically from the beginning. And so, returning to Chapter 5 of the Essay, we find that Locke still had this distinction in mind 20 years later: saying "truth is twofold: either purely Verbal and trifling . . .or Real and instructive." (576) Yet if this is how verbal and real truths were to have been understood all along, what are we to make of those definitions of real and chimerical truths which follow in Section 8 and 9?

Well, perhaps our mistake has been to think of them precisely as definitions in the first place. For, as we've already noted, there is a relationship between the type of proposition-trifling and instructive--and the ideas it contains. First of all, any truth about chimerical ideas can only be trifling. And this is, indeed, what Locke tells in us Section 8 . Truth "will be only Verbal when they (the words) stand for Ideas in the Mind, that have not an agreement with the reality of things." (577) This need not be read as a definition of verbal truths. In fact, verbal truths have at this point already been identified as trifling truths, in Section 6 . We might, therefore, restate this "definition" as "when the words joined stand for chimerical ideas, then the truth is only verbal or trifling." which is far from saying that all verbal truths contain chimerical ideas. Rather, verbal truths are those which are only about our ideas, which class all chimerical truths necessarily fall into.

Similarly, we may wonder about the second definition Locke here gives of real truths. Already, real truths have been equated with instructive truths; and, as we've seen, instructive truths must contain real ideas. Locke's words: "And so far as these ideas, thus marked by Sounds, agree to their Archetypes, so far only is the Truth real." (578) Again, this is not necessarily a definition of real truths, but instead may be considered a stricture upon them. For it may be read as indicating that truths can be real only if they contain real ideas: that there are no real truths which do not contain real ideas. Or, to put it another way, the class of real truths does not exist beyond the class of truths which contain real ideas; it only extends 
so far. ${ }^{17}$ To rephrase Locke: "So far only is truth real: so far as the ideas marked by sounds agree to their Archetypes."

Indeed, as we've seen, there is a large class of truths which contain real ideas but which provide no knowledge of reality, for they are not instructive, being only "of our imagination within us, and the transactions of our own thoughts in our breasts." (B.86-87) ${ }^{18}$ Trifling truths which contain real ideas make up a large part of the class of barely verbal truths, as Locke's numerous examples on Chapter 8 make clear. Yet Locke's discussion, in the Essay, and Draft A, indicates that these trifling propositions which contain real ideas are nevertheless not to be considered real. A real truth is something more than just a truth which contains real ideas.

Nevertheless it must be admitted that Locke's meaning in Section 9 is obscure. The words "so far ... so far only" might be read as indicating that "if and only if the ideas are real is the truth to be considered real." Such a reading is in fact supported by Section 8: "Then it is they contain real Truth, when these signs are joined, as our Ideas agree; and when our Ideas are such, as we know are capable of having an Existence in Nature." Trifling truths which contain real ideas pretty clearly meet these standards: or at least, they do when we know the ideas they contain are real. It would not, of course, take much to make this sentence accord with what is said elsewhere: a simple mention that the agreement/ disagreement must not be one of identity/diversity, or that the one idea must not contain the other, would suffice to make it clear that these real truths are the same instructive truths mentioned in Section 6.

Unfortunately, Locke has not made such an addition, and we are left with a disagreement between what is here said about truths containing real ideas, and what elsewhere is said about trifling truths which contain real ideas. The latter class, which falls under the first, is not called, "real," but "only verbal." We can speculate that this conflict might have arisen somewhat as follows. Given, as we've seen in Draft A, that Locke all along had in mind the distinction between verbal-trifling and real-instructive truths, perhaps later, when noting the relationship between these truths and the ideas they contain, he added sections, such as those in Chapter 5, Section 8-9. We may note that nothing like these sections appear in Draft $A, B$, or $C$, while there are clear affinities between Draft $A$ and the discussions of trifling/instructive truths in the Essay. Perhaps he meant for sections 8 and 9 to simply make clear this relationship between propositions and ideas; but unfortunately, what may have seemed a clear explanation to Locke's mind has not been so clear for us.

17Thanks to Mark Kulstad for his interpretation.

${ }^{18}$ John Locke, An Essay Concerning the Understanding, Knowledge, Opinion, and Assent, ed. Benjamin Rand (Cambridge: Harvard University Press, 1931). 
Yet it is also certainly possible that Section 8 and 9 are meant to be definitions. If so, we may wonder why Locke felt the need to include them, given that the distinction between verbal-trifling and real-instructive truths seems to have been his central concern all along. Locke may have already answered this question for us. For the distinction between chimerical and real truths is made in response to an objection: that all truths may be only of "the Chimaeras of Men's Brains." (577) This objection is particularly forceful if we consider Locke's claim that truths which "are instructive, are uncertain, and such as we can have no knowledge of their real Truth." (615) We have, in other words, almost no knowledge of instructive truths about substances, most of our knowledge being only of trifling truths, which as we've seen, are only of the ideas in our minds. Perhaps Locke hesitated to make so strong a claim; perhaps these objections were real ones made by early critics of the Essay, so that Locke felt the need to "soften" his theory of knowledge by allowing that we have some certainty of real truths.

If this is the case, Locke's classification of truths amounts to something like this:

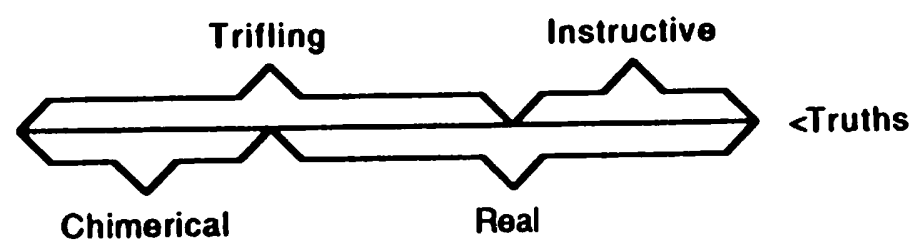

All truths containing chimerical ideas must be trifling; and all instructive truths must contain real ideas. Yet there are also trifling truths which may be considered real because of the ideas they contain. Still, this new distinction between chimerical and real truths may be only a superficial one, intended to make the Essay more acceptable. For the primary twofold division between trifling and instructive truths still remains, and the former, Chapter VIII makes clear, tell us nothing of reality whether or not they contain real ideas. Allowing that such truths may be called real, because they contain real ideas, does not amount to much. As we saw earlier, "A Negro is a Man" and "A Negro is not a Man" might both be considered real and be true, depending on the signification of the words. But if both are trifling, they still teach us nothing of reality.

However Locke intended these passages, the following relationship between propositions and the ideas they contain is clear. Trifling and instructive propositions are distinguished by the type of connection that exists between the ideas signified in a proposition. Truth is trifling where the connection is one of identity-diversity; that is, where the proposition either joins the ideas, when one is contained in the other; or separates them, if one idea is not contained in the other. Such truths are only verbal; only 
about the ideas in our mind, whether or not those ideas happen to be real. Truth is instructive, however, where agreement is expressed between ideas although one idea is not contained in the other, in which case the connection between the ideas must be of some other sort besides identity. In particular, when talking about substances, the only non-identity connections possible are those due to the real essence. Therefore, since chimerical ideas have no real essence, truths about them can only be trifling, only verbal. Instructive truths, meanwhile, must contain real ideas, all reaching beyond our ideas to speak of connections in reality. Hence, on our chart, we have eliminated the class of chimerical instructive truths, and have shown that both sorts of trifling truth are to be joined under the heading "only verbal."

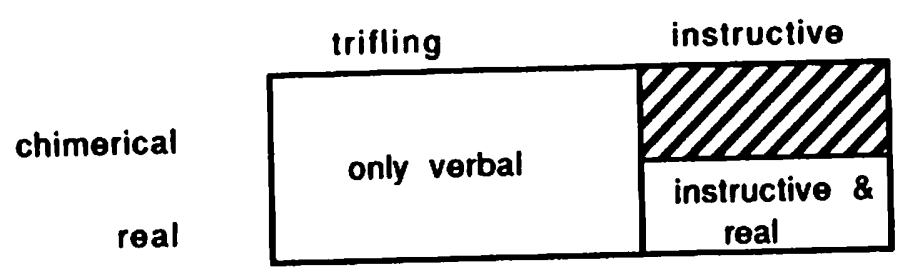

This, to conclude, explains Locke's confusing use of signs: why chimerical truths are called verbal, which is the label also for trifling truths, and why instructive truths are also called real. ${ }^{19}$

${ }^{19} \mathrm{My}$ thanks to Mark Kulstad and Susanna Goodin for their help on this paper. 